A CRÍTICA DO JOVEM SCHELLING À TEOLOGIA DE TÜBINGEN NO CONTEXTO DA QUERELA DO PANTEÍSMO

Ulisses Razzante Vaccari.

NOTÍCIAS

INSTRUÇÕES PARA OS AUTORES .200

CONTENTS.

\section{O AUTÔMATO ESPIRITUAL NA FILOSOFIA DE ESPINOSA IMPLICAÇÕES DE UMA ONTOLOGIA IMANENTISTA NO PLANO DO CONHECIMENTO CIENTÍFICO*}

José Ezcurdia**

Resumo: O presente texto tem como objetivo explicitar algumas das implicações da ontologia imanentista de Espinosa relativamente a sua concepção do conhecimento científico e em particular a sua noção de autômato espiritual. Nesse sentido revisam-se noções como sustância, causa imanente, definição genética; noções que lastram nossa reflexão em torno da concepção espinosana de ciência, na qual a ideia e a figura da verdade refletem uma identidade ou interioridade entre os planos do ser e do conhecer, entre o objeto e o sujeito mesmo de conhecimento.

Palavras chave: sustância, imanência, ciência, autômato espiritual.

A filosofia de Espinosa, por sua extrema complexidade e profundidade, ao longo da história foi objeto das mais variadas interpretações: materialistas e espiritualistas, racionalistas e intuicionistas; nietzschianos e hegelianos, entre outras grandes correntes de pensamento, disputaram a rica herança que ela representa. Nas últimas décadas, autores fundamentais como Gilles Deleuze (5) voltaram sua atenção às posições do filósofo holandês. Assim mesmo, pensadores como Negri (9), Bove (3), e Yovel (18), dedicaram interessantes estudos sobre aspectos diversos da filosofia de Espinosa, tornando patente sua vigência e sua extraordinária fertilidade enquanto fonte de ideias que nutrem os debates relativos não só à gênese e à forma da modernidade como também a preocupações de ordem contemporânea, como a filosofia política, por exemplo.

* Traducão de Homero Santiago.

** Professor da Universidade de Guanajuato, México. 
Pela própria riqueza representada pela doutrina de Espinosa, é difícil sequer realizar um resumo da grande variedade de autores e estudos que the dedicam sua atenção. Basta dizer que para os nossos fins apoiamos nossa abordagem de Espinosa com o concurso da recuperação de algumas posições de Cassirer, ligadas a uma reflexão articulada digamos numa "via epistemológica", relativa às exigências conceituais que acompanham a emergência da nova ciência, as quais a partir de nosso ponto de vista ganham em alcance teórico e se ampliam desde um ângulo propriamente ontológico.

\section{$* * *$}

Espinosa, a partir da noção de imanência, funda uma concepção do sujeito de conhecimento peculiar articulada na figura do autômato espiritual, que vem a nutrir a forma de uma nova ciência que faz frente ao desmoronamento do pensamento escolástico. $\mathrm{O}$ autômato espiritual é o aríete com o qual nosso autor, uma vez que faz estilhaçar o edifício lógico-epistemológico em que se sustentam a filosofia e a ciência medievais, mostra as diretrizes de uma ontologia em que a noção de imanência, identificando Deus à natureza, impulsiona o estabelecimento de uma noção de lei natural que, ao passo que dá conta do dinamismo da própria natureza, supõe um sujeito autônomo e ativo. A natureza não é para Espinosa uma forma degradada que participa de uma Ideia transcendente, mas, de um lado, coração de um sujeito capaz de dar lugar a ideias que possuem a verdade como critério intrínseco; por outro, objeto de um conhecimento científico no sentido moderno do termo, em que a definição genética, implicando justamente a noção de lei natural, vê no movimento não uma forma do não-ser ou um mero acidente contingente, mas genuíno objeto de estudo, na medida em que apresenta de modo diáfano a forma mesma de Deus ou da substância.
Revisemos algumas teses espinosanas a fim de explicitar esses pontos. Espinosa nos diz no livro I da Ética relativamente à noção de imanência:

Deus é causa imanente, mas não transitiva, de todas as coisas. Todas as coisas que são, são em Deus e devem conceberse por Deus; portanto, Deus é causa das coisas que são nele [...] Ademais, afora Deus, não pode dar-se nenhuma substância, isto é, nenhuma coisa afora Deus, que seja em si [...] Deus é, pois, causa imanente, mas não transitiva, de todas as coisas. (Spinoza 14, Ética, I, prop. XVIII e dem.)

Para Espinosa, Deus ou a substância se constitui como causa imanente da natureza, e nessa medida identifica-se com ela. Deus é causa imanente, de modo que se encontra não parcial mas totalmente presente em seu efeito mesmo, a própria natureza, que já não depende de nenhum princípio ou fundamento transcendente para adquirir substancialidade. ${ }^{1}$

É justamente com base na noção de substância como causa imanente que Espinosa desfralda sua concepção do sujeito e do conhecimento racional. Ele assinala que o sujeito, enquanto modo finito do atributo pensante, determina-se fundamentalmente por sua capacidade de conhecer. O conhecimento surge como forma do sujeito, por ser este um modo em que o atributo divino do pensamento se expressa e se constitui como tal.

O filósofo nos diz a respeito:

A essência do homem é constituída por certos modos dos atributos de Deus, a saber, por modos de pensar, a ideia de todos os quais é anterior por natureza e, dada ela, os demais modos (ou seja, aqueles aos quais a ideia é anterior por natureza) devem dar-se no mesmo indivíduo; e, portanto, a ideia é o que constitui o ser da alma humana. (Spinoza 14, Ética, II, prop. XI, dem.) 
O sujeito é uma modificação do atributo do pensamento, ou seja, uma ideia pela qual é possível o conhecimento, em termos de princípio e apreensão de diversas representações. A ideia aparece como forma da alma, por ser o princípio das representações a partir das quais o sujeito afirma sua própria capacidade de conhecer. Nesse sentido, o sujeito mesmo, justamente enquanto modo do atributo pensante, não pode conhecer mais que ideias e representações, dado que cada atributo concebe-se como uma substância em seu gênero e, por isso, não mantém comunicação com nenhum outro. Espinosa aponta que o objeto de conhecimento do sujeito são conceitos ou ideias, já que ele não poderia conhecer os modos de outros atributos, dado que existe uma incomunicação entre eles. Espinosa não vê no entendimento uma tela em branco, na qual se plasmassem as formas provenientes da sensibilidade para reconfigurar-se como conceitos universais, mas nele vê uma força pensante, um pensamento ativo como o atributo de que é modificação e expressão, capaz de criar seus próprios objetos. Ao caráter passivo do conceito aristotélico-tomista que se atualiza graças à experiência sensível, Espinosa opõe o caráter ativo da ideia que expressa imediatamente o dinamismo da substância que se manifesta no próprio atributo do pensamento. A ideia espinosana é essencialmente dinâmica e autônoma, pois é a substância mesma que satisfaz sua forma como afirmação, ao constituir-se e dar lugar ao sujeito mesmo como modo do atributo pensante. ${ }^{2}$

Espinosa nos diz no livro II da Ética:

Por ideia entendo um conceito da alma, que a alma forma por ser uma coisa pensante.

Digo conceito em vez de percepção, porque o nome percepção parece indicar que a alma padece em virtude do objeto; por outro lado, conceito parece expressar uma ação da alma. (Spinoza 14, Ética, II, def. III e explicação)
A ideia é para Espinosa âmbito expressivo e constitutivo da substância. A noção de imanência, nesse sentido, coloca-se como princípio da concepção de uma ideia ativa, que manifesta diáfana e imediatamente a forma mesma da natureza: a ideia não tem sua origem na impressão de uma pretensa substância que fosse a união de forma e matéria (no sentido aristotélico do termo), e que aparecesse como desencadeadora da atualização do conceito universal, mas no caráter produtivo da razão que torna patente a substância mesma ou Deus como causa imanente.

Para nosso autor a ideia, por ser um modo do atributo pensante, possui as condições para dar lugar ao conhecimento adequado e com este à verdade. A tradicional definição da verdade como adequação da mente à coisa cai perante uma ideia que, tendo como fundamento a substância, possui ela mesma a própria verdade de modo intrínseco: natureza, ideia e verdade são interiores entre si, na medida em que a substância como causa imanente manifesta-se completa e imediatamente em seu efeito, a saber, na verdade mesma enquanto determinação intrínseca da ideia que é a forma mesma do sujeito. ${ }^{3}$

Espinosa nos diz a respeito:

Por ideia adequada entendo a ideia que, considerada em si, sem relação com o objeto, tem todas as propriedades ou determinações intrínsecas de uma ideia verdadeira. (Spinoza 14, Ética, II, def. IV)

Dado o caráter imanente da substância espinosana, a verdade não pode ter lugar senão na ideia. A verdade não é resultado de um desdobramento lógico-dialético que culminasse na apreensão de uma essência transcendente ao sujeito e à natureza. Pelo contrario, o sujeito é o âmbito de emergência da verdade, pois ele se constitui como modo do atributo pensante que deixa ver sem mediação alguma a forma de seu princípio. 
Nesse contexto, Espinosa aponta que a verdade é uma dimensão própria da ideia que graças aos critérios cartesianos de clareza e distinção torna-se efetiva. Tais critérios são diretrizes metodológicas que ordenam a epistemologia espinosana, na medida em que guiam a determinação de uma verdade que se desdobra no interior e só no interior da ideia: a exigência da determinação dos elementos simples que dão lugar ao composto característico do método situa-se numa epistemologia em que a coerência interna entre as ideias desloca a própria adequação da mente à coisa como horizonte constitutivo da própria verdade.

Nesse sentido Espinosa assinala:

Não devemos temer fingir algo, se podemos perceber de um modo claro e distinto [...] A ideia do fictício não pode ser clara e distinta, mas é sempre confusa, e toda confusão procede de que a mente conhece só precisamente algo que em realidade é composto e integrado de partes e não se distingue o conhecido e o desconhecido ou não atenta à distinção das muitas partes que se contêm em uma coisa. (Spinoza 15, p. 60)

A clareza e a distinção aparecem como os critérios de uma verdade que reflete a forma da ideia como domínio constitutivo da substância, na medida em que operam justamente sobre uma série de conteúdos que não são mais que a própria ideia que satisfaz seu caráter ativo. Noutros termos, Espinosa recolhe os critérios cartesianos de clareza e distinção, pois sua concepção de uma ideia ativa não compreende nenhuma exterioridade, seja como forma transcendente, seja como certa empiricidade, que aparecessem como horizonte de sua contrastação.

Espinosa amplia essas posições ao assinalar que o sistema lógicoescolástico, valendo-se da experiência sensível para formar os conceitos universais, supõe uma inadequação fundamental, pois a experiência objetos. Para nosso autor a determinação da forma de um objeto a partir da sensibilidade requereria indagar a causa desse objeto no objeto finito anterior que foi causa dele e, destarte, remontar de maneira ilimitada, até sua lei natural. Isso é impossível, tanto pela finitude do próprio sujeito e de sua sensibilidade mesma, quanto pelo caráter inesgotável da cadeia causal que se estabelece na ordem das coisas finitas. A experiência sensível fica descartada da forma do conhecimento adequado, dado que perde o sujeito numa rede inesgotável de causas mediatas e não assinala as causas próximas, as leis naturais, eternas e infinitas, que atuam como causa mesma dos objetos.

Para Espinosa, conhecer algo é conhecê-lo por sua essência, isto é, por sua causa próxima. Por isso o conhecimento sensível, dado que só revela causas mediatas, é incapaz de gerar uma verdade sobre os objetos ou modos finitos.

Nesse sentido nosso autor aponta:

Da duração das coisas singulares, que se encontram fora de nós, não podemos ter nenhum conhecimento, senão muito inadequado.

Com efeito, cada coisa singular, tal como o corpo humano, deve ser determinada por outra coisa singular a existir e agir de maneira certa e esta, por sua vez, por outra, e assim ao infinito. Posto que na proposição precedente demonstramos, por essa propriedade comum das coisas singulares, que da duração de nosso corpo não temos senão um conhecimento muito inadequado, dever-se-á, pois, concluir o mesmo acerca da duração das coisas singulares, a saber, que dela não podemos ter senão um conhecimento muito inadequado. (Spinoza 14, Ética, II, prop. XXXI e dem.) 
A sensibilidade é fonte de inadequação, já que apresenta a causa e a forma das coisas de maneira mutilada e confusa. A natureza sensível do corpo mesmo não serve de princípio para determinar a essência dos objetos, já que por seu caráter finito só pode ocasionar um conhecimento parcial de sua forma, e não das leis que são seu princípio. ${ }^{4}$ Para Espinosa a ideia adequada, ao expressar imediatamente a substância, possui de maneira intrínseca a verdade, sem necessidade de levar-se a cabo contrastação empírica alguma. A razão espinosana, por contar com uma ontologia imanentista, alcança uma confiança tal em seu próprio movimento dedutivo que prescinde de toda perspectiva experimental. Tanto pela concepção ontológica do paralelismo e do fundamento comum entre os atributos extenso e pensante, como pela forma da ideia adequada enquanto expressão de um sujeito que é modo do atributo pensante, a ideia espinosana obtém para si uma suficiência ontológica que se constitui como âmbito cabal da determinação da verdade.

Espinosa aponta a respeito:

O verdadeiro não se distingue do falso unicamente por uma denominação extrínseca, mas antes de tudo por uma denominação intrínseca. Se algum artesão, por exemplo, concebe corretamente um utensílio, ainda que não se possa chegar a fazê-lo nunca, seu pensamento é verdadeiro, exista ou não o utensílio. (Spinoza 15, p. 64)

Em sua Correspondência o filósofo afirma:

Entre a ideia verdadeira e a adequada, não reconheço nenhuma outra diferença senão esta, que o termo verdadeira leva em conta somente a concordância da ideia com seu objeto (pensado) e o termo adequada, em troca, a natureza da ideia em si mesma; de modo que, na realidade, entre a ideia verdadeira e a adequada não há nenhuma diferença, afora essa relação extrínseca. (Spinoza 13, carta LX, p. 342)

Espinosa estabelece um dedutivismo em que tanto o paralelismo entre os atributos quanto a concepção da ideia ativa asseguram uma concordância da ideia mesma com seus objetos: os atributos, ao correr em linhas paralelas, garantem uma correspondência entre as essências objetivas e as essências formais, sempre e quando a própria razão goze de um método fundado na clareza e distinção que oriente seu reto desdobramento. Para Espinosa a ideia é autônoma, e nessa autonomia radica a fonte de uma verdade que não obstante dá conta dos modos do atributo da extensão; subtrai-se, como dissemos, à exigência de toda contrastação empírica que validaria seu conteúdo.

Nosso autor não só corta pela raiz a definição escolástica de verdade como adequação da mente à coisa, como anula também a noção de causa final, na qual a essência ou ideia mostra a passagem da potência ao ato de uma substância (união de forma e matéria) determinada. A concepção de conhecimento adequado e de uma ideia que possui a verdade de maneira intrínseca anula a concepção de uma causa final que faz das coisas particulares a degradação de um princípio transcendente: a noção de causa final associa-se a uma metafísica e uma epistemologia ancoradas, digamos, num realismo estéril que não reconhece na substância uma causa imanente à natureza e na ideia um caráter ativo capaz de produzir e dar conta de seus objetos.

Espinosa nos diz na Ética:

Acrescentarei ainda o seguinte, a saber, que essa doutrina do fim subverte totalmente a Natureza. Pois o que na realidade é causa, o considera como efeito, e vice-versa. Ademais, o que por natureza é anterior, o faz posterior. E, por último, o que é supremo e perfeitíssimo, o faz imperfeitíssimo. 
Pois, como é claro, é perfeitíssimo aquele efeito que é produzido imediatamente por Deus, e quantas mais causas intermédias algo precisa para ser produzido, tanto mais perfeito é. Porém, se as coisas que foram imediatamente produzidas por Deus tivessem sido feitas para que Deus alcançasse um fim, então, as últimas, por causa das quais se fizeram as anteriores, seriam as mais excelentes de todas. (Spinoza 14, Ética, I, apêndice)

A noção de causa final, supondo uma essência imóvel e transcendente como forma dos particulares, implica uma concepção do movimento na qual este se resolve como mero acidente. Nesse sentido tanto a natureza como o sujeito veem escamoteada sua forma peculiar enquanto um movimento e uma afirmação que expressa a forma mesma da substância. A crítica que Espinosa lança à noção de causa final restitui ao movimento uma densidade ontológica sem a qual não é possível pensar a forma mesma de um sujeito ativo nem a de uma multiplicidade que se vertebra sob a figura da lei natural.

Nesse campo convém tornar expresso o sentido da definição genética cunhada por Espinosa. A definição, ao dar conta dos objetos, há de assinalar justo sua causa eficiente, isto é, as próprias leis da natureza que aparecem como seu princípio construtivo. A substância, sendo causa imanente, afirma-se como causa eficiente das coisas finitas e objeto de uma definição que há de mostrar o motor formativo de seus objetos. ${ }^{5}$

Para ilustrar essas posições, Espinosa oferece o exemplo da definição de um círculo que alcança sua forma, não pela soma ilimitada de ângulos, mas por um raio que gira sobre um de seus extremos:

Agora, para saber de qual ideia de uma coisa, entre muitas, podem-se deduzir todas as propriedades do objeto, só observo um princípio: que a ideia ou definição da coisa expresse a causa eficiente. Por exemplo, para investigar as propriedades do círculo, indago se da ideia do círculo, que se supõe, consta de infinitos retângulos, se pode deduzir todas as suas propriedades; indago, digo, se essa ideia explica a causa eficiente do círculo. Como não ocorre isso, busco outra coisa, a saber, que o círculo é um espaço descrito por uma linha, de que um dos pontos está fixo e o outro móvel. Pero, como esta definição expressa a causa eficiente, sei que posso deduzir dela todas as propriedades do círculo. (Spinoza 13, carta LX, p. 342)

Para Espinosa as coisas são como são não na medida em que participam de uma essência transcendente que seria seu princípio, mas na medida em que desenvolvem o conteúdo das leis natureza que são seu fundamento imanente e que se afirmam nelas à maneira de uma causa eficiente. Espinosa nega toda causa final e identifica as causas formal e eficiente, satisfazendo tanto as exigências metafísicas cobradas pela concepção de uma natureza que não reconhece senão a si mesma como causa, quanto o perfil de uma razão ativa que, ao dar conta das próprias leis da natureza, ilumina com seu movimento dedutivo o processo construtivo de seus objetos.

O filósofo, ao estabelecer uma definição genética que tem como meta mostrar a causa eficiente dos modos finitos, lança por terra a lógica de gêneros e espécies em que o gênero mesmo desdenha o expediente formativo dos objetos. Espinosa desmantela a lógica de gêneros e espécies que privilegia a vagueza do conceito universal em detrimento de uma causa formal que, ao mesmo tempo em que se determina como causa eficiente, é também objeto da própria lei natural que dá conta do movimento mesmo em que se constituem as coisas finitas.

Espinosa nos diz na Reforma do entendimento: 
Há de mostrar-se brevemente que a diferença que existe entre a essência de uma coisa e a essência de outra é a mesma que existe entre a atualidade ou existência da mesma coisa e a atualidade ou essência de outra. Querer conceber a existência de Adão pela existência mais geral é igual a atentar para natureza do Ente em geral a fim de conceber a essência de Adão, definindo-o como ente. Ou seja, quanto mais em general se concebe a existência, mais confusa se nos apresenta e mais fácil será aplicá-la a qualquer objeto. (Spinoza 15, p. 16)

Na Ética ele sublinha:

De causas semelhantes nasceram, ademais, essas noções que se chamam universais, como homem, cavalo, cão, etc., a saber: porque no corpo humano se formaram ao mesmo tempo tantas imagens, por exemplo de homem, que excedem sua força de imaginar, em verdade não por completo, porém o bastante para que a alma não possa imaginar as pequenas diferenças dos seres singulares (a saber, a cor, o tamanho de cada um). (Spinoza 14, Ética, II, prop. XL, esc. I)

Espinosa desenvolve uma crítica à lógica de gêneros e espécies que vem realçar a uma concepção imanentista em que a noção de lei natural supõe uma natureza que se tem a si mesma como fundamento: a natureza contém em si as regras de seu próprio desdobramento, a razão mesma não há de postular uma essência transcendente em relação à qual esta apareça como mero devir, privação ou uma forma com uma profunda insuficiência ontológica. A lógica de gêneros e espécies é incapaz de dar conta dos objetos, pois deixa de lado o motivo construtivo dos mesmos, em prol do estabelecimento de um edifício lógico-metafísico articulado pela noção de transcendência. Espinosa qualifica a lógica de gêneros e espécies como um conhecimento imaginativo, no qual campeiam a obscuridade e a confusão. Ele formula uma crítica nominalista à lógica aristotélico-tomista, ao assinalar que os universais de modo algum podem dar conta das leis da natureza que aparecem como causa eficiente dos objetos. A lógica de gêneros e espécies, a noção de Deus transcendente, as causas finais, em suma o conjunto do arcabouço conceitual da filosofia escolástica, resultam de um conhecimento inadequado, produto da imaginação que não responde ao caráter ativo do entendimento.

Espinosa aponta na Reforma do entendimento.

Até agora distinguimos a ideia verdadeira das demais percepções e fizemos ver que as ideias fictícias, falsas, etc., têm sua origem na imaginação, isto é, em certas sensações fortuitas (por assim dizer) e separadas, que não procedem da força mesma da mente, mas de causas externas [...] Podeis entender por imaginação o que vos agradar, contanto que se conceba algo diferente do entendimento e que põe a alma na situação de um ser passivo. (Spinoza 15, p. 73)

A imaginação, do ponto de vista de Espinosa, está na base da filosofia escolástica, já que esta torna opaca a determinação da forma singular dos modos finitos a partir de uma série de conceitos universais e causas finais que não reconhecem neles uma expressão das leis da natureza. A filosofia escolástica, vendo uma separação entre a natureza e seu princípio e privando a razão de seu caráter autônomo e ativo, constituise como um produto da imaginação em que a dialética e a lógica de gêneros e espécies deslocam a própria claridade e distinção que acompanham o cabal desdobramento da razão. ${ }^{6}$

Nesse sentido, Espinosa lança mão da matemática justamente como paradigma de um conhecimento adequado. A matemática, uma vez que não sujeita a forma de seus objetos à realização de pretensas causas 
finais à maneira da própria lógica de gêneros e espécies, mostra o princípio formativo dos objetos, precisamente enquanto uma causa formal que se afirma como causa eficiente.

Espinosa nos diz na Ética:

Donde terem passado a dar como certo que os juízos dos Deuses superam em muito a capacidade humana, isto, sem dúvida, teria sido a única causa de que a verdade ficasse eternamente oculta ao gênero humano, se a Matemática, que não trata de fins, mas tão-só das essências e propriedades das figuras, não tivesse mostrado aos homens outra norma da verdade. (Spinoza 14, Ética, I, apêndice)

Pois bem, Espinosa assinala que o entendimento, ao dar lugar à ideia adequada, estabelece digamos a matéria sobre a qual construirá uma nova ideia que, por sua vez, determinar-se-á como objeto sobre o qual o entendimento mesmo satisfará seu caráter ativo: o entendimento para Espinosa possui um caráter indefinidamente produtivo pelo qual dá acabamento a sua forma enquanto modo do atributo pensante. $O$ trabalho da razão para Espinosa se levanta como a criação de conceitos que se engendram, se combinam e se explicam indefinidamente, dando à luz progressivamente uma verdade que se afirma como conhecimento adequado.

Espinosa nos diz a respeito:

A ideia verdadeira (temos uma ideia verdadeira) é distinta de seu ideado [ou objeto] representado: uma coisa é o círculo e outra a ideia do círculo, pois esta não é algo que tenha periferia e centro como o próprio círculo; uma ideia de algum corpo tampouco é algo corporal. Sendo algo totalmente diverso de seu objeto, a ideia será, por si mesma, algo inteligível; a ideia, com respeito à sua essência formal, pode ser objeto de outra ideia objetiva, por sua vez, esta essência objetiva, considerada em si, será também algo real e inteligível e assim indefinidamente. (Spinoza 15, p. 42)

Para Espinosa a ideia, ao colocar-se como objeto de si e constituirse como expediente para novas ideias que por sua vez serão objeto de outras ideias, articula-se em uma estrutura processual que a orienta num desdobramento aberto e sustentado. A uma dialética e uma lógica escolástica que aspiram a um repouso na apreensão do conceito universal, Espinosa opõe um conhecimento de corte matemático que em seu próprio movimento dá conta de seus objetos.

Ele explicita tais considerações ao comparar o movimento da razão com o progresso tecnológico, pelo que todo produto do trabalho e a investigação se constituem como instrumentos da criação de novos produtos e investigações mais avançadas:

No princípio, os homens lograram, laboriosa e imperfeitamente, a realização de certos trabalhos valendose dos instrumentos que a natureza lhes oferecia; depois fabricaram outros mais difíceis, com menor esforço e maior perfeição, e, procedendo gradualmente em novas realizações e maior perfeição, chegaram a produzir com pouco esforço as coisas mais difíceis. Assim também o entendimento forjase por si mesmo seus instrumentos espirituais, mediante os quais adquire a capacidade de realizar outras novas obras espirituais e, destas obras, outros instrumentos ou capacidades de ulteriores investigações [...]. (Spinoza 15, p. 41)

Para a Espinosa a razão não se determina como um desdobramento dialético que vá do particular ao universal, da sensibilidade à ideia, mas como um progresso indefinido em que faz valer seu caráter ativo. Para nosso autor a verdade não surge ao final de uma suposta ascensão do múltiplo ao uno, mas no interior da razão mesma que retorna 
sistematicamente sobre seus conceitos e promove o firme relevo das essências objetivas e das essências formais, desenvolvendo a forma do atributo pensante que é seu fundamento.

É a partir dessas considerações que Espinosa cunha sua concepção do sujeito como "autômato espiritual". O autômato espiritual é um sujeito autoprodutivo que se constitui na progressiva construção de conceitos que possuem precisamente a verdade como critério intrínseco. O autômato espiritual aparece como manancial da verdade, pois é a natureza mesma que com ajuda do próprio método cartesiano da clareza e distinção pode dar lugar ao conceito em que se afirma o caráter autônomo e ativo do entendimento. ${ }^{7}$

Espinosa nos diz na Reforma do entendimento:

É o mesmo que disseram os antigos, ao afirmar que a verdadeira ciência procede da causa ao efeito, se bem que nunca tenha chegado a conceber, que eu saiba, a alma como um agente que observa certas leis à maneira de um autômato espiritual; por isso desde o princípio, quanto nos foi possível, adquirimos um conhecimento de nosso intelecto e de uma norma tal da ideia verdadeira que nos dê a segurança de não confundi-la com as falsas ou fictícias. (Spinoza 15, p. 74)

O autômato espiritual é o fundamento de um conhecimento adequado, pois expressa a verdade mesma, o conteúdo das leis da natureza, nas quais o objeto se realiza. Espinosa coloca a verdade no coração do entendimento, pois este enquanto autômato espiritual, sendo ele mesmo natureza, dilui em seu firme movimento e no combinar-se de suas ideias a distinção entre as essências formais e as essências objetivas, entre o sujeito e o objeto mesmo de conhecimento. A ciência e o real são interiores entre si, pois o sujeito, ao pensar o real, desenvolve-o e afirma-o justamente ao dar lugar à ideia que apresenta a verdade como critério intrínseco: o real é a ideia e a ideia expressa o real. A substância se manifesta no modo do atributo pensante e o modo enquanto autômato espiritual que dá lugar à lei natural não só manifesta, mas também aparece como registro constitutivo da substância.

A noção espinosana de autômato espiritual possui profundas implicações de ordem ontológica, pois este, ao desdobrar-se, é o real que se afirma e se determina como tal. A passagem da substância ao atributo pensante, e deste às leis da natureza e aos modos finitos de dito atributo, ordena-se numa relação imediata pelo qual a substância mesma identificase com o próprio autômato espiritual, com a própria ideia que aparece como seu âmbito expressivo e domínio de sua determinação. A verdade possui um caráter auto-evidente que reflete a forma de um sujeito autoprodutivo em que a substância patenteia seu caráter imanente. O desenvolvimento da ideia é o desenvolvimento do real que no sujeito como autômato espiritual dá acabamento a sua forma. ${ }^{8}$

Espinosa nos diz na Ética:

No escólio da prop. XI desta parte explicou-se o que é a ideia da ideia; porém há de notar-se que a proposição anterior é suficientemente manifesta por si, pois ninguém que tenha uma ideia verdadeira ignora que a ideia verdadeira implica a suma certeza. Com efeito, ter uma ideia verdadeira não significa nada mais que conhecer uma coisa perfeitamente, ou seja, o melhor possível; e ninguém, por certo, pode duvidar disso a não ser que creia que a ideia é algo mudo, como uma pintura sobre uma tela, e não um modo de pensar, a saber, o entender mesmo, e, pergunto, quem pode saber que entende uma coisa a não ser que entenda antes as coisa?, isto é, quem pode saber que está certo de uma coisa a não ser que antes esteja certo das coisas? Ademais, o que pode ser mais claro e mais certo como norma da verdade, que a ideia verdadeira? Sem dúvida, assim como a luz manifesta a si mesma e manifesta as trevas, assim a verdade é norma de 
si e do falso. (Spinoza 14, Ética, II, prop. XLIII e esc.)

Espinosa estabelece uma concepção do conhecimento científico que apresenta um duplo suposto ontológico pelo qual tanto o objeto como o sujeito possuem um caráter dinâmico e construtivo: o objeto enquanto expressão das leis da natureza e o sujeito enquanto autômato espiritual capaz de dar lugar à ideia adequada. Objeto e sujeito expressam a forma de Deus ou da substância como causa imanente. Sem embargo, objeto e sujeito tornam patente sua identidade precisamente na figura de um autômato espiritual que ao dar conta das leis da natureza leva adiante seu próprio desdobramento: para Espinosa a essências objetivas e as essências formais identificam-se não só na medida em que os atributos guardam um rigoroso paralelismo, como ainda porque o sujeito é natureza e a natureza é sujeito. Para nosso autor, fazer ciência é dar conta da afirmação na qual a natureza se constitui, justamente ao afirmá-la. O autômato espiritual de Espinosa, sua noção de lei natural e com elas sua concepção geral do conhecimento científico não só supõem diversos postulados ontológicos, mas são eles mesmos, seja-nos permitida a expressão, desenvolvimento ou afirmação do real, pois a verdade aparece como núcleo da ideia em que a substância enquanto causa imanente manifesta-se e determina-se exatamente como substância.

Espinosa ergue um racionalismo filosófico em que a noção de autômato espiritual vincula imediata e interiormente as dimensões do ser e do conhecer sob uma relação dinâmica: o conhecer afirma o ser e o ser afirma-se como conhecer. Segundo Espinosa o sujeito, ao dar conta do real, não há de dobrar-se mais à forma de uma pretensa essência imóvel e transcendente, mas o real ou a substância encontram no sujeito mesmo como autômato espiritual a via de seu desenvolvimento e determinação. O racionalismo espinosano surge como uma filosofia imanentista e idealista que desarma a arquitetura lógico-metafísica da filosofia escolástica, traçando assim uma das diretrizes fundamentais - a figura mesma de um sujeito autônomo e ativo - que vertebram a forma da modernidade nascente.

\section{THE SPIRITUAL AUTOMATON IN SPINOZA'S PHILOSOPHY: IMPLICATIONS OF AN IMMANENT ONTOLOGY IN THE FIELD OF SCIENTIFIC KNOWLEDGE}

Abstract: The aim of the present text is to make known certain implications of Spinoza's immanentist ontology in relation to his conception of scientific knowledge, in particular his conception of the spiritual automaton. From this position, notions such as substance, immanent cause, genetic definition are revised, notions that document our reflection on Spinoza's conception of science in which the ideia and the figure of truth reflects the identity or inwardness between the dimensions of being and knowing, between the object and subject of knowledge.

Keywords: substance, immanence, science, spiritual automaton

\section{REFERÊNCIAS BIBLIOGRÁFICAS}

1. ALBIAC, G. La sinagoga vacía. Un estudio de las fuentes marranas del spinozismo. Madri: Hiperión, 1987.

2. ALLENDESALAZAR, O. Spinoza: filosofia, pasiones y política. Madri: Alianza, 1988.

3. BOVE, L. La stratégie du conatus. Affirmation et résistance chez Spinoza. Paris: Vrin, 1996.

4. CASSIRER, E. "Spinoza”. In: El problema del conocimiento. Cidade do México: FCE, 1965.

5. DELEUZE, G. Spinoza y el problema de la expresión. Barcelona: Mario Muchnik, 1975.

6. . Spinoza, Nietzsche, Kant. Barcelona: Labor, 1974.

7. JAQUET, C. L'unité du corps et de l'esprit. Affects, actions et passions chez Spinoza. Paris: PUF, 2004.

8. MACHEREY, P. Avec Spinoza. Études sur la doctrine et l'histoire du spinozisme. Paris: PUF, 1992. 
9. NEGRI, A. La anomalía salvaje. Ensayo sobre poder y potencia en B. Spinoza. Barcelona: Antropos-UAM Iztapalapa, 1993.

10. RAMOND, C. Le vocabulaire de Spinoza. Paris: Ellipses, 1999.

11. ROUSSET, B. "L'être du fini dans l'infini dans la philosophie de Spinoza". In: Revue de philosophie, $\mathrm{n}^{\circ}$ 18, 1986.

12. ___ .Les implications de l'identité spinoziste de l'être et de la puissance". In: Spinoza: Puissance et ontologie. Paris: Kimé, 1994.

13. SPINOZA. Correspondencia. Madri: Alianza, 1988.

14. _. Ética. Cidade do México: FCE, 1958.

15. _. Tratado de la reforma del entendimiento. Buenos Aires: Aguilar 1959.

16._._. Tratado político. Madri: Técnos, 1985.

17._. Tratado teológico-politico. Madri: Alianza, 1990.

18. YOVEL, Y. Spinoza, el marrano de la razón. Madri: Anaya y Mario Muchnik, 1995.

\section{NOTAS:}

1. Cf. Deleuze 5, p. 171, onde o autor assinala os nexos históricos da expressão e da imanência em função da determinação de sua forma e relação no pensamento de Espinosa. A respeito, ele aponta: “a ideia de expressão dá conta da verdadeira atividade do partícipe, e da possibilidade da participação. É na idéia de expressão que o novo princípio da imanência afirma-se. A expressão surge como a unidade do múltiplo [...] Deus se expressa a si mesmo no mundo; o mundo é a expressão, a explicação de um Deus [...] que é o ser ou do Uno que é."

Deleuze situa a noção de explicatio no pensamento de Espinosa na linha de um conceito de emanação neoplatônica que evoluiu até a imanência. Deus como causa, aparece não parcial mas totalmente em seu efeito. O efeito não é, assim, uma degradação da causa, mas a expressão na qual ele se constitui como tal. Espinosa, ao adotar a noção de imanência, em simultâneo adere à tradição neoplatônica, renova-a e outorga-lhe uma nova orientação.

2. Cf. Cassirer 4, p. 23, onde se analisa o caráter ativo da ideia espinosana: "Nesse tipo de conhecimento, o intelecto já não é algo condicionado, mas o elemento condicionante. A 'idéia' adquire agora a significação e a importância que o sistema maduro de Espinosa lhe atribui. A idéia não deve ser depreciada como se fosse a imagem muda pintada num quadro, mas sim nasce na afirmação ou na negação. É, pois, antes um conceito que uma imagem, deve ser chamada de 'conceptus' e não de ‘perceptio', já que só assim exprimimos que não é algo que seja dado de fora, mas que deve sua origem pura e exclusivamente ao espírito.”

3. Cf. Rousset 11, p. 232, sobre a relação imanente e a interioridade dos diferentes momentos em que se constitui a ontologia de Espinosa: "Em resumo, segundo a ontologia da primeira parte da Ética, o ser infinito e único, na infinidade de suas ordens infinitas de existência [atributos], é, segundo as modalidades infinitas das determinações de sua existência [leis], nas modalidades finitas de seu ser que são as concreções [modos], extrinsecamente determinadas, mas capazes de receber determinações intrínsecas das modalidades infinitas de determinação. Nesse edifício impressionante não há mediação a encontrar, pois não há mediação a buscar; não há mediação porque as relações dos termos não são relações entre os seres, mas relações do ser no ser, suas ordens de existência e suas modalidades de existência, suas leis infinitas e sua concreção no infinito; é precisamente isso que significa a determinação de uma substância una e única, ao mesmo tempo que infinita, a redução das substâncias cartesianas [extensão e pensamento] ao ser atributivo, a redução dos indivíduos substanciais ao ser modal, e a promoção das leis da natureza à categoria de modos eternos; é por isso também que o ser do finito no infinito, em seu ser real, positivo e ativo, não é um 'participar', mas um 'ser parte de'."

4. Cf. Cassirer 4, p. 24: "Claro está que o que tem que dar a norma, para [levar a cabo] um conhecimento certo, não é nosso saber empírico limitado e incoerente, nem tampouco o caráter e a técnica da lógica escolástica habitual. O método escolástico da formação de conceitos, ainda que pareça contrapor-se ao simples empirismo, compartilha com este, sem embargo, um aspecto fundamental e decisivo; trata-se de chegar ao conhecimento 'abstrato' do geral por meio da comparação do concreto. Contudo o que se obtém, ao entrelaçar e definir desse modo as múltiplas imagens das coisas concretas, não é tanto uma representação geral de conjunto, senão uma representação global, vaga e confusa. A simples comparação do concreto jamais nos revela as condições e os fundamentos que o constituem e o estruturam".

5. Cf. Cassirer 4, p. 25, com relação à forma da definição genética espinosana: "Tratase de reter o ser individual concreto enquanto tal; em toda a sua determinabilidade e peculiaridade, porém compreendendo-o ao mesmo tempo como o produto de leis necessárias e universais. Não devemos, portanto, adotá-lo simplesmente como um dado fixo, mas devemos criá-lo construtivamente com base em seus fatores fundamentais. Só contemplando-o dentro dessa conexão necessária, chegaremos a formar-nos uma 
ideia verdadeira e adequada de seu ser. Todo conhecimento verdadeiramente criador é portanto um conhecimento sintético, parte dos elementos primários, simples, para combiná-los de um determinado modo, com sujeição a leis, levando-o desse modo até novos conteúdos do saber. O pensamento só pode chegar a compreender plenamente o que deste modo brota do pensamento mesmo [...] Daqui provém, de um modo interiormente consequente, a teoria da definição que Espinosa desenvolve em seu estudo sobre o modo de melhorar o entendimento [...] Toda autêntica definição é [...] genética, não se limita a copiar um objeto existente, mas torna manifestas as leis de sua própria formação".

6. Cf. Rousset 12, p. 11, que sublinha o caráter ativo do entendimento, enquanto fonte da ideia adequada, em oposição ao caráter passivo ou potencial do mesmo na filosofia aristotélica: "Em suas duas últimas partes, a Ética nos ensina que o Bem e a Beatitude se definem pela realização de nossa potência, da 'Potência do Entendimento ou da liberdade do Homem'; o Tratado da reforma do entendimento expõe mais particularmente a tese segundo a qual nossas ideias verdadeiras, por oposição àquelas que são fictícias, falsas ou duvidosas, são os 'produtos' da 'potência de nosso espírito', isto é, da 'potência de nosso entendimento', não sendo este mais que nosso espírito enquanto é ativo. Essas são afirmações essenciais do sistema espinosano, que lhe caracterizam em face de outros filósofos, e das quais Espinosa era perfeitamente consciente; porém elas se ligam a uma reflexão mais geral, quiçá menos explicitamente desenvolvida, menos aparente, reflexão de ordem ontológica, relativa à noção mesma de potência, sobre o ser da potência, e por consequência sobre a relação da potência e o ser, e que é fundamental e de todo originária.

O espinosismo postula, com efeito, uma identidade da potência e do ser que implica uma identificação do ser em potência e em ato, em franca ruptura com o ensinamento tradicional aristotélico que prevalecia à época, segundo o qual o ser em potência constitui um ser menor que o ser em ato, na medida em que o ser não é ainda na realidade, na medida em que se encontra privado da existência efetiva...".

7. Cf. Cassirer 4, p. 25, com relação à figura do autômato espiritual: "Assim, pois, permanece em vigor aqui a definição aristotélica de ciência, segundo a qual esta é o conhecimento dos efeitos partindo das causas; porém o que Espinosa acrescenta a ela e o que ele mesmo sublinha expressamente como necessário complemento é isto: que o espírito, nesse progresso das causas aos efeitos, não se acha determinado e compelido de fora pelas coisas, mas que obedece exclusivamente a sua própria lei lógica. A alma é um autômato espiritual que atua livremente, em concordância com leis, seguindo determinadas regras inerentes a ele.”
8. A respeito, cf. Yovel 18, p. 223, que sublinha a dimensão ontológica da ideia em Espinosa, enquanto desdobramento de Deus ou da substância: "Para cumprir seu papel a primeira ideia vera não pode apoiar-se em signos exteriores de verdade: deve conter sua própria justificação. Isso faz pensar na evidência cartesiana das 'ideias claras e distintas' (que Espinosa também subscreve). Cotnudo, nem sequer essas servem. A ideia verdadeira básica de Espinosa só tem sentido se seu objeto é causa ôntica de si mesmo; ou seja, se é a totalidade do universo tomada como Deus. Começamos pelo reconhecimento de que Deus é idêntico a tudo o que existe, e portanto é a única substância existente: substância necessária, causa de si e eterna, que abarca todos os aspectos e dimensões da realidade, incluídas aí mente e matéria, extensão e pensamento, finitude e infinitude, e assim por diante. Desse ponto se desdobra o restante do sistema, e todas as ideias específicas do universo seguem-se da explicação interna da primeira ideia abrangente." 